REVISTA APOTHEKE

v.6, n.1, ano 3, julho de 2017

ISSN 2447-1267

\title{
SOBRE O ENSINO/APRENDIZAGEM EM ARTES VISUAIS OU ARTE COMO EXPERIÊNCIA 46
}

Fábio Wosniak (UDESC)

fwosniak@gmail.com

Jociele Lampert (UDESC)

jocielelampertauol.com.br

\begin{abstract}
RESUMO
Este artigo apresenta algumas reflexões acerca dos conceitos de Arte como Experiência e os processos de ensino/aprendizagem em Artes Visuais, tangenciando os campos da Arte, Arte Educação e ensino de pintura, tendo como eixo a abordagem metodológica que vem sendo pesquisada no Grupo de Estudos Estúdio de Pintura Apotheke e nas aulas de Graduação e Pós-Graduação em Artes Visuais na Universidade do Estado de Santa Catarina - UDESC.
\end{abstract}

Palavras-chave - Arte como experiência. Ensino/aprendizagem em Artes Visuais. Arte e Arte Educação.

\section{ABSTRACT}

This article presents some reflections on the concepts of Art as Experience and teaching / learning processes in Visual Arts, tangentially the art fields, Art Education and painting teaching, having as axis the methodological approach that has been researched in the study group Apotheke painting studio and the graduation classes and Graduate Studies in Visual Arts at the University of the State of Santa Catarina - UDESC .

Keywords - Art as experience. Teaching / learning in Visual Art. Art and Art Education.

Artes Visuais como experiência ou o pensamento de Dewey como base teórica.

A obra de John Dewey, Art as Experience, publicada e originalmente editada por Jo Ann Boydston (1934), teve sua tradução para a língua portuguesa em 2010, pela Editora Martins Fontes. Antes da publicação do pensamento filosófico de Dewey sobre uma Filosofia da Arte no Brasil, o autor já era precursor das reformas de ensino em diversos Estados brasileiros.

\footnotetext{
46 Trabalho apresentado e publicado no SEMINÁRIO COMEMORATIVO DO CENTENÁRIO DO LIVRO DEMOCRACIA E EDUCAÇÃO na Faculdade de Educaçnao da Universidade de São Paulo, 2016. Disponível em: http://www.uel.br/eventos/centenariode/pages/arquivos/Anais_Seminario_ $\mathrm{DE} \cdot \mathrm{pdf}$
} 


\section{REVISTA APOTHEKE}

\section{v.6, n.1, ano 3, julho de 2017 \\ ISSN 2447-1267}

Diante dos debates acerca do pensamento deweyiano para a Educação, tem sido relevante refletir que seus estudos sobre Educação e Arte, por mais que tenham sido formulados antes da primeira metade do século XX, continuam expressivos para a contemporaneidade, tendo em vista que uma de suas ideias expoentes é a de que "a arte é o locus paradigmático dos valores, e a criação e o prazer advindo da arte são o protótipo dos objetivos dignos da condição humana" (DEWEY, 2010, p. 10).

A filosofia pragmática de Dewey não se refere exclusivamente à ação, mas o que o autor deflagra nesta corrente pragmática é uma teoria filosófica do pensamento e do sentimento, onde o pensamento norteia a ação e o sentimento reconhece as consumações dispostas por ela - uma conscientização unificada pelo sentir e agir. John Dewey foi o filósofo norte-americano mais relevante da primeira metade do século XX. Seu pensamento baseava-se principalmente na conviç̧ão moral de que "democracia é liberdade" - uma sociedade democrática prepara todos os indivíduos, de maneira igualitária, assegurando seus benefícios, por meio de variadas formas da vida associada. Nessa perspectiva, a educação deve proporcionar aos sujeitos um interesse sobre as questões sociais e culturais, inerentes ao espírito humano, permitindo assim que as mudanças sociais aconteçam sem ocasionamentos de desordem (DEWEY, 1959).

Para o filósofo, a configuração da disposição humana pode ser possível diante de diversos agentes, mas a escola, segundo o autor, ainda é o espaço chave para que uma filosofia da experiência se concretize como uma "realidade manifesta". Uma filosofia da experiência no âmago da Educação exige que professores sejam conhecedores exímios do seu processo de aprender, e que estejam com seus conjuntos de práticas em constante estado de reflexão. Caso 


\section{REVISTA APOTHEKE}

\section{v.6, n.1, ano 3, julho de 2017 \\ ISSN 2447-1267}

contrário, corre-se o risco de que sua prática pedagógica não passe de um aglomerado de dogmas sem qualquer exame crítico (DEWEY, 2011). Dessa forma, Dewey sustenta a ideia de que nenhuma reflexão sobre processos educacionais seja viável sem levar em conta os contextos nos quais estes estejam inseridos.

No tocante à Arte, Dewey apresenta questões relevantes para os professores. Em uma publicação de 1998, o autor se pergunta como a Arte "ajudaria a viver melhor a vida cotidiana. Ele [Dewey] se pergunta: como professores de todas as áreas poderão fazer uso de "lições" de arte (entendidas em termos experienciais) para melhorarem o seu ensino?" (BARBOSA, 2001, p. 20-21).

A prerrogativa mais importante para pensarmos na atualização do conceito de experiência cunhado por Dewey é a de recusar as verdades absolutas e as dicotomias. Dewey defende um princípio de continuidade em toda sua filosofia, onde essa continuidade confere uma unidade, que nada se aproxima de imutabilidade. Para Dewey, unidade implica flexibilidade e continuidade de interações (AMARAL, 2007).

Amaral (2007, p.39) explica que a unidade na teoria deweyiana trata

$$
\begin{aligned}
& \text { (...) de uma unidade apoiada na flexibilidade das } \\
& \text { interações e aqui poderíamos perfeitamente } \\
& \text { acrescentar a palavra "sociais, sem que com isso } \\
& \text { estivéssemos prejudicando a clareza do pensamento } \\
& \text { do autor, mas, pelo contrário, reforçando-a. trata- } \\
& \text { se ainda de uma unidade que pressupõe a diversidade } \\
& \text { e poderíamos igualmente acrescentar, dos } \\
& \text { "espíritos", sem incorrer em qualquer distorção do } \\
& \text { seu pensamento. }
\end{aligned}
$$

A unidade presente na filosofia de John Dewey une a relação do indivíduo ao meio, aquela entre o homem e o mundo. Compreender o conceito de unidade presente na filosofia deweyiana torna-se fundamental para apreender o conceito de Arte como experiência e de Estética. Dewey não 


\section{REVISTA APOTHEKE}

\section{v.6, n.1, ano 3, julho de 2017 \\ ISSN 2447-1267}

abandona as qualidades holísticas, historicistas e organicistas na sua filosofia. O autor busca as "origens estéticas nas necessidades naturais, na constituição e nas atividades do organismo vivo" (SHUSTERMAN, 1988, p. 233). A estética pragmatista de John Dewey, segundo Shusterman (1988, p. 231), "ocupa a posição ideal para reorientar e revigorar a filosofia da arte contemporânea". De acordo com - primeiro, "as oposições entre mente e corpo, alma e matéria, espírito e carne originam-se todas, fundamentalmente, no medo do que a vida pode trazer" (DEWEY, 2010, p. 89).

Assim, já vemos esboçada uma contraposição com as teorias dualistas (corpo x alma, teoria x prática), ou seja, com aquelas teorias estéticas onde os valores principais eram os de praticar distinções entre Arte e Vida. Dewey considera a criatura viva em toda a sua totalidade, cabendo uma filosofia que compreenda a articulação do homem com o seu meio, onde a experiência é a "chave-mestra" para revelar a vitalidade unificada da experiência singular e estética entre o homem e a Arte.

A noção de Arte presente na obra de John Dewey reside na relação que a criatura viva tem com seu ambiente, o naturalismo deweyiano torna-se necessidade para toda obra de Arte. Neste sentido, a função da Arte é unificar a vitalidade consciente presente na vida humana, pois as obras de Artes qualificadas não geram experiências estéticas especializadas - elas aprimoram a percepção, a comunicação, originando fontes de energia e inspiração. A experiência estética é a responsável em ampliar e aprimorar todas as inquietações humanas. Shusterman (1998, p. 238) explica que a função da Arte para Dewey:

(...) não residem em algum fim particular, especializado, mas sim em satisfazer a criatura viva de maneira global, servindo a fins variados e, acima de tudo, aumentando a nossa experiência 


\title{
REVISTA APOTHEKE
}

\author{
v.6, n.1, ano 3, julho de 2017 \\ ISSN 2447-1267 \\ imediata, que nos revigora e vitaliza, assim, a \\ realizar qualquer fim que busquemos.
}

Para John Dewey, a arte deveria se situar ao lado das coisas da experiência comum da vida, ou seja, inserida em um contexto diretamente humano, ao contrário de estarem relegadas exclusivamente aos museus ou galerias, compartimentalizadas em teorias que distanciam as experiências estéticas da vida cotidiana, ou seja, do prazer pessoal que, segundo o autor, está próximo às coisas da natureza, como o ar, o solo, a luz, as flores. Seriam desses lugares que brotariam as coisas esteticamente admiráveis. (DEWEY, 2010) .

A filosofia da Arte defendida por Dewey reestabelece a união entre as formas mais sofisticadas do artístico com os sentimentos mais ordinários da vida humana. A constante interação entre sujeito e ambiente, juntamente com os resultados dessa relação, será o que constituirá uma experiência. Na relação entre a Arte e a Estética, o filósofo afirma que o trabalho poético, desenvolvido em uma perspectiva da filosofia da experiência, seria o clímax da sofisticação entre a união dos saberes - afetivo, intelectual e prático (DEWEY, 2002). Na perspectiva do filósofo, as Artes oferecem vitalidade e aprofundam o conhecimento das experiências acumuladas, porque

\footnotetext{
[t]oda arte envolve órgãos físicos, como o olho e a mão, o ouvido e a voz e, no entanto, ela ultrapassa as meras competências técnicas que estes órgãos exigem. Ela envolve uma ideia, um pensamento, uma interpretação espiritual das coisas e, no entanto, apesar disto é mais do que qualquer uma destas ideias por si só. Consiste numa união entre 0 pensamento e o instrumento de expressão. (DEWEY, 2002, p. 76).
}

É justamente na integração entre o pensamento e o instrumento de expressão que se pode esboçar uma ideia do que o autor nos comunica a respeito da experiência 


\section{REVISTA APOTHEKE}

\section{v.6, n.1, ano 3, julho de 2017 \\ ISSN 2447-1267}

singular/estética. A experiência para Dewey é um processo do viver que relaciona-se de maneira intensa e contínua entre o mundo e o sujeito. Dessa relação brotam conflitos, resistências, impressões. Destes elementos, por sua vez, emergem as experiências, envoltas em ideias e emoções. É, portanto, neste conceito instaurado por Dewey que uma filosofia da experiência para a Arte/Educação contemporânea torna-se pertinente.

A experiência singular é também uma experiência estética, tendo em vista que em ambas as experiências há consumação, e nunca cessações - como no caso de uma experiência intelectual. Neste sentido, a experiência intelectual é diferente da experiência singular/estética. A primeira tem como matéria-prima símbolos e signos, e exige uma conclusão, um encerramento. É justamente por sua natureza conclusiva que gera incertezas. Ao contrário, a experiência singular/estética reside em fluxos constantes, possui lugares de repouso, unidade, e o seu desfecho é atingido por um movimento ordeiro e organizado. O material vivenciado, ao mesmo tempo em que é marcado pelas percepções, é transformado pelas experiências anteriores. "A conclusão é uma consumação, e não uma cessação. Esta experiência carrega um caráter individualizador e autossuficiente." (DEWEY, 2010, p. 110)

A experiência singular/estética é uma espiral, seu fluxo contínuo unifica a percepção entre o que é feito e o que é suportável; cria conexões com experiências anteriores - uma observação constante entre o que existiu, existe e existirá, o processo é vivenciado conscientemente. A ansiedade e as frustações, que fazem parte da vida cotidiana e estão presentes no processo criativo, não são impeditivas para que a inteligência organize a consumação da experiência pulsante; discernimento entre ações e desejos, não há dicotomias, fragmentações entre 


\section{REVISTA APOTHEKE}

\section{v.6, n.1, ano 3, julho de 2017 \\ ISSN 2447-1267}

inteligência e sensibilidade. Tudo se relaciona, tudo está junto, é o próprio processo do viver unificado ao ambiente tomando consciência de si - esse conjunto consciente propicia ao sujeito uma experiência singular/estética. o estético, na filosofia da arte de John Dewey, não é um fator externo e que se "lança" para a experiência. Tampouco está relacionado ao luxo, ou é idealizado por qualquer corrente de pensamento transcendental. Para o autor, "o estético (...) é o desenvolvimento esclarecido e intensificado de traços que pertencem à toda experiência normalmente completa (...) estético refere-se à experiência como apreciação, percepção e deleite" (DEWEY, 2010, p. 125127).

Dewey afirma que "a arte, em sua forma, une a mesma relação entre o agir e o sofrer, entre a energia de saída e a de entrada, que faz com que uma experiência seja uma experiência" (DEWEY, 2010, p. 128). Como o artístico está relacionado ao ato de produção e o estético ao ato de prazer e percepção, uma obra acontece em sua completude quando o artista, ao trabalhar, assume essas duas atitudes transformando-a em uma só, ou seja, numa atitude artísticoestética. O artista, na concepção de Dewey,

\footnotetext{
comparado a seus semelhantes, é alguém não especialmente dotado de poderes de execução, mas também de uma sensibilidade inusitada às qualidades das coisas. Essa sensibilidade também orienta seus atos de criação". (DEWEY, 2010, p. 130).
}

O que está em questão é o controle do desejo. Na ideia inicial até será possível pensar em tudo, mas o "tudo" não é possível na relação que se pretende produzir - o artista encontra os obstáculos, as dificuldades da produção. Saber produzir neste limite da existência humana é aprender que a relação entre pensar e agir, culminando em uma experiência singular/estética e compreendendo que experiência não é uma 


\section{REVISTA APOTHEKE}

\section{v.6, n.1, ano 3, julho de 2017 \\ ISSN 2447-1267}

soma entre o emocional e intelectual, mas que ambos ocorrem inseparavelmente, é uma das modalidades mais exigentes do pensamento. Chegar na consumação desta experiência é proteger o trabalho de uma mera sucessões de excitações (DEWEY, 2010). Sendo assim, a experiência singular/estética presente nos escritos de John Dewey é o lugar onde o autor nos esclarece sobre a proximidade desse conceito com o campo das artes e do trabalho do artista.

Dewey desafia toda a tradição filosófica acerca do conceito de estética. O autor coloca o estético, assim como as Artes, nas origens da existência humana. Ele revela que a experiência singular/estética deve estar nos processos normais do viver, nas coisas cotidianas da vida. Segundo Dewey (2010, p. 72), "se as obras de arte fossem colocadas em um contexto diretamente humano na estima popular, teriam um atrativo muito maior do que podem ter quando as teorias compartimentalizadas da arte ganham aceitação geral". O autor afirma ainda que "a genuína arte se desenvolve a partir do trabalho do artesão" (Dewey, 2002, p. 76), defendendo que o grande desenvolvimento proporcionado por um trabalho estético-artístico está associado à vida cotidiana, nas coisas simples (DEWEY, 2002).

É desse lugar, que os pressupostos filosóficos dewyiano falam de uma Filosofia da Arte como experiência. Consciente desse processo, a experiência possibilita ao indivíduo uma reorganização que o coloca em contato com outras formas de apreender a vida. Por isso, a experiência singular/estética é inerente à consumação, e nunca a uma conclusão. Entende-se por consumação "um certo nutrir-se" constantemente da experiência que no seu fluxo-refluxorepouso avança para novas reformulações, onde outras percepções irão envolver esses atos e ideias de pensamento. O pensar também ocorre em fluxos, esses fluxos são fases carregadas de afetividade; não são evoluções, mas variações 


\section{REVISTA APOTHEKE}

v.6, n.1, ano 3, julho de 2017

ISSN 2447-1267

móveis (DEWEY, 2010).

No caso específico das Artes Visuais, a percepção é o sentido mais comum por onde os conteúdos de uma obra são "absorvidos". Em toda experiência singular/estética, tocamos o mundo através de um órgão específico. Será a partir desse órgão que a percepção encontrará o fluxo para operar em toda a sua energia. Essa, provocada exclusivamente pela obra de Arte, é "a maior realização intelectual da história da humanidade" (Dewey, 2010, p. 93). O autor nos explica que:

A obra de arte provoca e acentua essa
caracteristica de ser um todo e de pertencer ao
todo maior e abrangente que é o universo em que
vivemos. Essa é, a meu ver, a explicação da
sensação de requintada inteligibilidade e clareza
que temos na presença de um objeto vivenciado com
intensidade estética. (Dewey, 2010, p. 351).

A arte reside no próprio processo do viver. O homem utiliza os materiais ofertados pela natureza com a intenção de significar sua existência no mundo e ampliar sua própria vida. A existência da Arte é prova de que o homem é capaz de nutrir-se conscientemente no plano do significado, intervindo com todo o seu organismo, regulando, selecionando e reordenando sua vida. A arte não está dissociada dos processos do viver, pois com ela, e a partir dela, conferimos sentido à nossa vida, revelamos desejos e geramos impulsos para continuarmos existindo com uma certa sensação de pertencimento no mundo.

Assim, a experiência estética/singular da qual nos fala Dewey transcreve-se também em dimensões pedagógicas, pois perpassa a escolha, a seleção e o repertório do espectador. Toda Arte, que busca novas maneiras de pensar o mundo, diferente dos sistemas tradicionais e hegemônicos do conhecimento, "precisa educar seu público em novos modos de percepção. Assim, a arte é essencialmente educativa, não 


\section{REVISTA APOTHEKE}

\section{v.6, n.1, ano 3, julho de 2017 \\ ISSN 2447-1267}

somente em seu aspecto instrumental, mas através do consumatório e do instrumental fundidos na experiência." (BARBOSA, 2001, p. 147)

É relevante salientar que este valor do ato expressivo, a matéria prima da experiência que Dewey revela em sua obra, tem grande aproximação com a organização das emoções e a objetividade. Porém, organização e objetividade, para o filósofo, não são "coisas simples" de serem alcançadas pelo organismo que, fragmentado pelo ambiente e imerso nas teorias reducionistas explora, na maioria das vezes, experiências incipientes.

A teoria deweyiana da Arte como experiência toma o argumento da aprendizagem em si mesma. Nesse conjunto da aprendizagem, o saber a consolidação do pensamento e da percepção são identificados como os fatores decisivos para que ela ocorra. Isso muitas vezes torna a filosofia da Arte como experiência distante dos discursos acadêmicos e escolares, tendo em vista o caráter totalmente utilitário e prático que estas instituições estão inseridas.

\section{o ensino e a pesquisa como reconstrução da experiência}

Refletir sobre o processo de ensino/aprendizagem no contexto do Ensino Superior, requer compreender que a pesquisa em Arte e Arte Educação envolve fazer perguntas e procurar respostas que permitam 0 entendimento de como produzir, estudar e ensinar arte.

De acordo com Sullivan (2005), na elaboração de métodos de investigação, educadores geralmente procuram adaptar práticas de pesquisa tradicional existentes nas ciências humanas. Por exemplo, no início dos anos 1960, arte educadores esforçaram-se na validação de uma teoria de campo (ARNESTINE, 1965; ECKER, 1965; EFLAND e EISNER, 1964 e KAUFMAN, 1959). A questão principal pairava sobre a Arte como disciplina e, se era possível construir um arcabouço 


\section{REVISTA APOTHEKE}

\section{v.6, n.1, ano 3, julho de 2017 \\ ISSN 2447-1267}

teórico com os quais as estruturas exploratórias de conhecimento poderiam ser sustentadas. Anos mais tarde, o uso de métodos de pesquisa qualitativa em pesquisa educacional encontrou espaço na Arte Educação (BRESLER, 1994; CHALMERS, 1981; EISNER, 1985 E 1991; MAY, 1993; STOKROCKI, 1997). Assim, a busca para basear a adequação da teoria de Arte Educação deu referências para o professor, como uma aceitável fonte de conhecimento, e a prática de sala de aula e a comunidade, como viáveis bases para reflexões de pesquisa. Esta aproximação fundamentada foi percebida como forma de avaliar mais de perto a autenticidade de aprender e ensinar arte. Como resultado, é notável que as concepções de Arte Educação mudaram, como os seus métodos, formas e modelos de pesquisa foram (ou estão sendo) adequados.

Para Pareyson (2001), há três definições de Arte, compreendendo o campo do saber e a área do conhecimento, sendo definições tradicionais, que se justapõem e coexistem, que são: Arte como fazer, como conhecimento e como expressão. Em diferentes tempos na História da Arte, a reflexão do pensamento sobre 0 conceito de arte multiplicaram-se e estenderam-se. "Estas diversas concepções colhem caracteres essenciais da Arte, conquanto não sejam isoladas em si e absolutizadas". (PAREYSON, 2001, p. 22 ).

No texto "A obra de arte e o espectador contemporâneo" de Alberto Tassinari (2001), o autor apresenta a relação Arte e técnica, e a condição da artisticidade da obra de arte em seu processo de elaboração e conclusão, tratando incluso de objetar, visto que a artisticidade poderá também ser atribuída pelo espectador e desvendado que não trata-se de dons artísticos, mas sim, a compreensão de que diante de uma obra pronta, há um processo anterior inteiramente responsável pela artisticidade, eixos que somente as duas 


\title{
REVISTA APOTHEKE
}

v.6, n.1, ano 3, julho de 2017

ISSN $2447-1267$

teorias sobre o fazer artístico vistas em Dewey (1934) e Pareyson (1954) evidenciariam:

\begin{abstract}
Numa tradição de índole aristotélica, por exemplo, - fazer da obra imita o proceder da natureza. Assim, quaisquer que sejam os processos evocados ou imitados e qualquer que seja a instância - mágica, religiosa ou natural - em que se apoiam, o fazer sempre esteve aliado a tais processos, tidos como mais elevados e que de algum modo guiavam a consecução das obras. Nesta irrelevância do fazer da obra parece haver uma relação com a espacialidade da arte naturalista. A última não imita, e portanto oculta, o seu fazer. Este não é sinalizado pela obra pronta. (TASSINARI, 2001, p.136.)
\end{abstract}

Desta forma, a abordagem metodológica que vem sendo pesquisada e desenvolvida semanalmente no Grupo de Estudos Estúdio de Pintura Apotheke, que se estende para a Graduação e Pós-Graduação em Artes Visuais, no que se refere o ensino da pintura, segue reflexões da Educação como reconstrução da experiência (DEWEY, 1971). Compreendese que experiência não é algo que se oponha a natureza, pela qual se experimente, ou prove a natureza. Experiência é uma fase da natureza, podendo ser uma forma de interação, pela qual dois elementos entram (situação/contexto e agente/sujeito) e assim, são modificados. Seguindo o pensamento de Teixeira \& Westbrook (2010, pág. 37), "não é possível separar vida, experiência e aprendizagem, pois simultaneamente vivemos, experimentamos e aprendemos". Nesta perspectiva, a experiência educativa é uma experiência inteligente (intelectual) em que participa o pensamento, através do qual se vêm a perceber relações e continuidade antes não percebidas. Ou seja, de acordo com Dewey (1934), o conceito de Educação é definido pelo processo de reconstrução e reorganização da experiência, pelo qual é atribuído sentido e com isto, habitam-se escolhas futuras.

Compreendendo Arte e Arte Educação como 


\section{REVISTA APOTHEKE}

v.6, n.1, ano 3, julho de 2017

ISSN 2447-1267

experiência, procuramos instaurar em nossas práticas educativas, metodologias que dialoguem, mas que também avancem para uma reflexão crítica do contexto e do próprio sujeito, que pese ser artista professor pesquisador.

Vinculando-se a disciplinas da Graduação em Artes Visuais, especificamente nas disciplinas sobre o ensino das artes Visuais, como cultura visual, estágios, sobre a introdução e processo pictórico, tem sido evidente que não somente saber as técnicas (teorias metodológicas) e os conteúdos (História da Arte), tem revelado que os estudantes, principalmente os da Licenciatura, desenvolverão uma reflexão crítica sobre a produção em Arte e, nem tampouco sobre o Ensino de Arte. Tal condição, de uma reflexão crítica sobre a prática docente em Artes Visuais, somente é gerada pelo condicionamento e articulação entre teoria e prática, no que confere de fato ação - saber/fazer e sobretudo - sentir/pensar. Sendo assim, uma das metodologias do Grupo de Estudo Estúdio de Pintura Apotheke, que tem sido levada as aulas da Graduação e da Pós-Graduação em Artes Visuais, tem sido a de partir de projetos práticos, que envolvem exercícios que compreendem processos plásticos e resolução de problemas, baseados sempre em exemplos de artistas. Os projetos são desenvolvidos de forma processual com finalidade avaliativa e os critérios são observados em cada etapa do trabalho. Não há uma separação entre quem ensina e quem produz, no sentido de reflexão crítica como condição de uma formação artística, tanto para professores, quanto para artistas.

Ancoramos nossa prática no sentido inverso: partimos do estudo de teorias, dos exemplos de artistas e adensamos - processo de construção plástica para a resolução de problemas de pesquisa, baseado em Arte. Compreendendo que o eixo gerador do fazer artístico é o trabalho e potência para a problemática da pesquisa que engendra o pensamento 


\section{REVISTA APOTHEKE}

v.6, n.1, ano 3, julho de 2017

ISSN 2447-1267

do artista professor.

O que ambas situações têm em comum é o espaço (no sentido físicol: ambas as aulas e projetos, são realizadas em um ateliê de pintura na Universidade. O que evidencia uma descontinuidade, no que tange sobre tudo a Pós-Graduação, não somente do sentido de possibilitar o desenvolvimento de estudos práticos, mas sobretudo da articulação real da teoria com a prática. O desafio de teorizar a prática (do estúdio de Arte), requer conforme Sullivan (2005), a construção de uma robusta e defensiva estrutura para considerar a relação entre as teorias e as práticas que dão conhecimento de como a Arte pode ser estudada/produzida e como pode ser ensina/aprendida. Ou seja, das relação entre teoria e prática, apontam-se:

- Primeiro, a identificação de um percurso de questões teóricas e uma ampliação do componente que interessa em evidenciar a noção de que a prática artística é um esforço de multidisciplinaridade, ancorada no fazer arte.

- Segundo, apenas uma estrutura pode servir como um fórum para considerar debates no campo e assegurar que os limites que constroem discussões em curso são assuntos para continua revisão.

- Terceiro, estudos de pesquisa que são aceitos podem ser fixados e criticados dentro do domínio particular de teoria e prática.

- Quarto, as mais recentes abordagens para pesquisa como o uso de métodos visuais (BANKS,2001; EMMISON \& SMITH,2000; PINK,2001; ROSE,2001) e análise de dados qualitativa por computador (FIELDING \& LEE, 1998; GAHAN \& HANNIBAL, 1998, TESCH, 1990) que podem ser avaliados em termos de domínio de teoria e prática em Arte Educação.

- Finalmente,

a estrutura

oferece 


\section{REVISTA APOTHEKE}

\section{v.6, n.1, ano 3, julho de 2017 \\ ISSN 2447-1267}

possibilidade que a prática de arte pode ser prontamente traduzida para outras disciplinas do discurso da pesquisa se o propósito exigir isto. Desta maneira a cultura da pesquisa permanece fundamentada nas teorias e práticas de arte.

Partindo do contexto de que todo objeto artístico poderá ter dimensões políticas, discursivas e pedagógicas, compreende-se que a pratica no ateliê de pintura, como processo de um fazer criativo, onde inclui-se a reflexão crítica e a produção plástica por meio da experimentação (e vice e versa) concebendo que a pintura poderá ser uma representação imaginária, mas também, que denota incontestavelmente derivações sobre a estética. Neste sentido, a pintura não é uma técnica, e sim uma tradição, porque seu saber/fazer também é um saber/julgar, ou formas de saber pensar, conforme Duve (2012, pág. 147).

O Grupo de Estudos Estúdio de Pintura Apotheke ${ }^{47}$ tem produzido para além de exposições, oficinas e micro práticas que ressoam o uso da referência de Dewey (1934) com o fazer pictórico, no sentido de evidenciar o conceito de experiência pelo processo de ensino/aprendizagem, visto que a pintura é tida como eixo gerador do pensar e do fazer, do saber/sentir e, além dos projetos finalizados que adentram escolas e outros ateliês, instaurando redes e conexões com projetos.

47 O Estúdio de Pintura Apotheke deriva suas ações de extensão, oferecendo oficinas de pintura, mini cursos com prática artística, conversas com artistas professores, aulas abertas e ações que visam oportunizar a prática pictórica. O objetivo é propiciar o estudo de processos pictóricos, bem como, da possibilidade de ensino que envolve a pintura, não como meio tradicional, mas sim, em um campo expandido. Desta forma, o espaço do estúdio torna-se ampliado para práticas, que envolvem a investigação artística, no ensino e processo de criação. As ações são desenvolvidas e organizadas em parceria com os participantes do Grupo de Estudos Estúdio de Pintura Apotheke (UDESC), do Grupo de Pesquisa [Entre] Paisagens e idealizadas, criadas e produzidas pela professora Dra. Jociele Lampert (DAV/PPGAV). Fonte: http: //www. apothekeestudiodepintura.com 


\section{REVISTA APOTHEKE}

\section{v.6, n.1, ano 3, julho de 2017 ISSN 2447-1267}

Desta forma, a concepção metodológica artística sobrevoa sobre o ensino e a pesquisa no campo das Artes Visuais, pois a pergunta que nos move é 'onde está Arte na Arte-Educação?'

Em disciplinas voltadas para o Ensino de Graduação, tanto para a formação pedagógica, quanto para a formação artística, tem sido trabalhado no sentido de apropriação ou colagem (conceitual), na produção de imagens e sons que compreendem o território artístico, objetivando formas de desenhar, publicar e fazer investigação, assim combinam estas qualidades a criação artística e o requerimento em formas de pesquisa ou projetos. Investigar problemas educativos por meio da criação artística, ou mesmo, pesquisar problemas artísticos por meio da própria linguagem artística, é uma forma de responder a pergunta que nos move. Tais questões podem assemelhar-se com abordagens como a investigação baseada em Arte, ou mesmo questões que permeiam a A/R/Tografia, no entanto, nossas reflexões sobre as concepções didático-pedagógicas decorrem dos estudos da Arte como Experiência.

\section{Referências}

AMARAL, Maria Nazaré de C. Pacheco. Dewey: Filosofia e experiência Democrática. São Paulo: Perspectiva, 2007. BARBOSA, Ana Mae. John Dewey e o Ensino da Arte no Brasil. São Paulo: Cortez, 2001.

DEWEY, John. Arte como experiência. São Paulo: Martins Fontes, 2010 .

- Democracia e Educação. São Paulo: Companhia Editora Nacional, 1959.

- A Escola e a Sociedade a Criança e o Currículo. Lisboa: Relógio D'água, 2002. - Vida e Educação. São Paulo: Melhoramentos, 1971 .

DUVE, Thierry de. Fazendo escola (ou refazendo-a?). Chapecó: Argos, 2012. 


\title{
REVISTA APOTHEKE
}

\author{
v.6, n.1, ano 3, julho de 2017 \\ ISSN 2447-1267
}

PAREYSON, Luigi. Os problemas da estética. São Paulo: Martins Fontes, 1984.

SHUSTERMAN, Richard. Vivendo a arte: o pensamento pragmatista e a estética popular. São Paulo: Editora 34, 1998 .

TASSINARI, Alberto. O espaço moderno. São Paulo: Cosac Naify, 2001.

WESTBROOK, Robert B. TEIXEIRA, Anísio. John Dewey (trad. e org. José Eustáquio Romão, Verone Lane Rodrigues). Recife: Fundação Joaquim Nabuco: Editora Massangana, 2010. Coleção Educadores (MEC). Disponível em:

http://www.dominiopublico.gov.br/download/texto/me4677.pdf

\section{FÁBIO WOSNIAK}

http://lattes.cnpq.br/6525393533253057

Doutorando em Artes Visuais - PPGAV/UDESC; Mestre em Artes Visuais - PPGAV/UDESC; Pedagogo S.E./2012 FAED/UDESC; Psicanalista; Vice-Coordenador da Rede de Educadores de Museus de Santa Catarina - REM/SC (Gestão 2013-2015), membro/pesquisador do Grupo de Pesquisa Entre Paisagem (UDESC/CNPQ) e do Grupo Arte na Pedagogia (Makenzie/SP), integrante do Grupo de Estudos Estúdio de Pintura Apotheke (UDESC).

\section{JOCIELE LAMPERT}

http://lattes.cnpq.br/7149902931231225

Desenvolveu pesquisa como professora visitante no Teachers College na Columbia University na cidade de New York como Bolsista Fulbright (2013), onde realizou estudo intitulado: ARTIST'S DIARY AND PROFESSOR'S DIARY: ROAMINGS ABOUT PAINTING EDUCATION. Doutora em Artes Visuais pela ECA/USP (2009); Mestre em Educação pela UFSM (2005). Possui Graduação em Desenho e Plástica Bacharelado em Pintura, pela Universidade Federal de Santa Maria (2002) e Graduação em Desenho e Plástica Licenciatura pela Universidade Federal de Santa Maria (2003). Professora Adjunta na Universidade do Estado de Santa Catarina. Atualmente é Coordenadora de Pós-Graduação em Artes Visuais Mestrado e Doutorado PPGAV/CEART/UDESC. 